\title{
Comparison of salbutamol given by intermittent positive-pressure breathing and pressure-packed aerosol in chronic asthma
}

\author{
PB ANDERSON, A GOUDE, MD PEAKE \\ From the Department of Respiratory Diseases, Lodge Moor Hospital, Sheffield
}

ABSTRACT A double-blind crossover study was performed to compare $4.8 \mathrm{mg}$ salbutamol given by pressure-packed aerosol and intermittent positive-pressure breathing nebulisation in chronic asthmatic patients. The two delivery techniques produced similar changes in respiratory function and pulse rates. Given equal effect, a high-dose pressure-packed aerosol would have advantages in cost and convenience over nebulisation techniques.

Interest has grown recently in the various methods available for the delivery of bronchodilators to asthmatics. Comparisons have been made between intravenous and nebulised bronchodilators in acute asthma $^{12}$ and between intermittent positivepressure breathing and non-pressurised nebulisation. ${ }^{3}$ Salbutamol given by pressure-packed aerosol and by nebulisation has been investigated in both acute $^{4}$ and chronic ${ }^{5}$ asthma and also in chronic bronchitis. ${ }^{6}$ The doses of bronchodilator used in these studies of different inhalational delivery techniques, however, have differed greatly, 200 or $400 \mu \mathrm{g}$ salbutamol by pressure-packed aerosol being compared with 5 or $10 \mathrm{mg}$ by nebuliser. More nearly equivalent doses given by the two methods have not been compared.

The calculation of equivalent doses is problematical because of variation in the amount of drug deposited in the respiratory tract by the systems. About $10 \%$ of a dose delivered from a pressurepacked aerosol is deposited in the lung, ${ }^{7}$ and it has been calculated that on average $25 \%$ of a dose given by intermittent positive-pressure breathing is available to the patient and about $12.5 \%$ of the dose is absorbed. ${ }^{8}$ We have investigated the effects of equal doses of salbutamol given by pressure-packed aerosol and intermittent positive-pressure breathing in asthmatics in a stable state; while accepting that it is probably not possible to ensure that identical quantities reach the lung, we believe that a reasonable approximation was achieved, to judge by present information. A triggered intermittent positive-

Address for reprint requests: Dr PB Anderson, Department of Respiratory Diseases, Lodge Moor Hospital, Sheffield S10 4LH. pressure breathing device was chosen to drive the $\vec{\oplus}$ nebuliser so that the amount of drug reaching the ? patient could be more closely controlled, nebulisation not continuing during the patient's expiratory phase.

\section{Methods}

We investigated 10 patients with chronic asthma in a $\stackrel{\circ}{3}$ stable state. The diagnosis of asthma was made on $\vec{F}$ clinical grounds and the subjects had previously been shown to have appreciable potential for reversal of their asthma, with an improvement of over 음 $15 \%$ in the forced expiratory volume in one second $\stackrel{叉}{x}$ $\left(\mathrm{FEV}_{1}\right)$ after $5 \mathrm{mg}$ salbutamol by nebulisation but a $\frac{0}{3}$ poor response to a dose of $200 \mu \mathrm{g}$ salbutamol from a pressure-packed aerosol. The mean improvement $ᄋ$ 20 minutes after $200 \mu \mathrm{g}$ salbutamol was $8.8 \%$ (SD $₹$ $4 \cdot 2$ ). Their mean age was 51.7 years (SD 8.72). One 윽 patient was taking inhaled corticosteroids and pred- $\rightarrow$ nisolone, seven inhaled corticosteroids and intramuscular triamcinolone, and two oral pred- N nisolone. All subjects gave informed consent.

Each patient received two treatment regimens in a 0 randomised double-blind crossover study. The $\underset{\omega}{N}$ treatments were given on different days, starting at $\bar{O}$ the same time of the day. The two regimens were 0

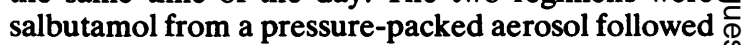
by placebo by intermittent positive-pressure $\stackrel{\infty}{+}$ breathing (Harlow Mk2, British Oxygen Co Ltd 0 IPPB device driven by a compressed air cylinder, $\frac{\vec{D}}{\mathbb{D}}$ and a Sandoz nebuliser) and placebo pressure- $\stackrel{\mathbb{Q}}{\stackrel{\perp}{\circ}}$ packed aerosol followed by salbutamol respirator $\stackrel{\mathbb{Q}}{\mathscr{Q}}$ solution by intermittent positive-pressure breathing. The patients were all familiar with the delivery sys- 
tems and investigatory techniques and had not had bronchodilators for six hours.

The solution was nebulised over 12-15 minutes. To take into account the possibility of differences in bronchodilator action in the later stages of nebulisation due to better drug penetration because of previously achieved bronchodilatation, the dose from the pressure-packed aerosol was also fractionated. The total dose from the pressure-packed aerosol was given over 10 minutes.

The pressure-packed aerosol used was a special high-dose salbutamol inhaler delivering $400 \mu \mathrm{g} /$ puff. Two puffs were given at two-minute intervals until a total of 12 puffs $(4.8 \mathrm{mg})$ had been given. Similarly, $4.8 \mathrm{mg}$, or the equivalent volume of placebo, were given by intermittent positivepressure breathing, the total volume being made up to $2 \mathrm{ml}$ with $0.9 \%$ saline.

The experimental design was as follows. Baseline measurements of $\mathrm{FEV}_{1}$ and forced vital capacity (FVC) were made (Monaghan M403, Sandoz Products Ltd), the best of three attempts being taken. Thoracic gas volume and airways resistance were estimated by whole-body plethysmography (PK Morgan Ltd) and the resting pulse rate was counted. The subject then took two puffs from the study pressure-packed aerosol, a slow expiration to residual volume being followed by a 10 -second breath hold after a maximal inspiration. Six double puffs were taken at two-minute intervals, a single measurement of $\mathrm{FEV}_{1}$ and FVC being taken immediately before the next inhalation. Spirometry and counting of the pulse rate were repeated at 15 minutes and at 30 minutes. At 45 minutes pulse rate, spirometry, and whole-body plethysmography were all repeated.

At 60 minutes from the beginning of the procedure the subject received the study solution nebulised by intermittent positive-pressure breathing. Spirometry was repeated at two-minute intervals until all the solution had been nebulised. At 75 minutes and 90 minutes the pulse rate was measured and spirometry carried out and finally at 105 minutes spirometry, pulse rate, and whole-body plethysmography were repeated. An identical protocol was followed on the second investigation day.

The results for $\mathrm{FEV}_{1}, \mathrm{FVC}$, thoracic gas volume, and pulse rate were analysed by paired $t$ test. Specific airway conductance (sGaw) was analysed after transformation to $\log _{\mathrm{e}} \mathrm{sGaw}$ by paired $t$ test as the distribution of sGaw is skewed. ${ }^{9}$

\section{Results}

One patient's baselines were found to vary by more than $15 \%$ after the code had been broken and his results were excluded from analysis. The following analysis is therefore based on nine subjects.

\section{SPIROMETRY}

The changes in FEV 1 with time for the two treatments (active inhaler followed by placebo nebulisation and placebo inhaler followed by active nebulisation) are shown in figure 1 . The baseline (time 0 ) on the two days did not vary significantly $(p>0 \cdot 3)$.

The active pressure-packed aerosol produced a significant improvement in $\mathrm{FEV}_{1}$ at 45 minutes compared with baseline $(p<0.03)$ but the placebo produced no significant change over the same period ( $p>0.3$ ). A significantly greater percentage change in $\mathrm{FEV}_{1}$ had occurred by 45 minutes after the active than the placebo aerosol $(p<0.035)$. There was no change in $\mathrm{FEV}_{1}$ between 45 and 60 minutes after the active aerosol $(p>0.7)$, nor did the placebo nebulisation produce further bronchodilatation $(p>0.4)$.

After the placebo pressure-packed aerosol the $\mathrm{FEV}_{1}$ at 45 minutes did not differ from baseline ( $p$ $>0.3$ ) nor did the 60 -minutes value differ from that at 45 minutes $(p>0 \cdot 4)$. Nebulisation of active solution was followed by a highly significant increase in $\mathrm{FEV}_{1}(\mathrm{p}<0.001)$. For the group, however, there was no significant difference in the percentage change in $\mathrm{FEV}_{1}$ after salbutamol from a pressurepacked aerosol and salbutamol by intermittent positive-pressure breathing nebulisation $(p>0.4)$.

The changes in FVC are shown in figure 2 and show a pattern similar to the $\mathrm{FEV}_{1}$ changes. The two delivery systems resulted in an identical rate of change in spirometry values. Within the group three patients tended to respond better to the nebuliser and two to the pressure-packed aerosol. The numbers are too small for further analysis but there was no clear relation to $F E V_{1}$ or other factor.

\section{WHOLE-BODY PLETHYSMOGRAPHY}

sGaw $\log _{e}$ sGaw and other plethysmographic results are shown in table 1 . The active pressurepacked aerosol produced a highly significant improvement in $\log _{e}$ sGaw $(p<0.002)$ and nebulised placebo solution did not result in a further change $(p>0.7)$. Placebo pressurepacked aerosol did not result in a significant change $(p>0.05)$ but nebulised salbutamol caused a significant improvement $(p<0.04)$. The baseline values of $\log _{e}$ sGaw on the two treatment days were significantly different $(p<0.025)$ but the percentage change after the active pressure-packed aerosol was highly significantly greater than after placebo pressure-packed aerosol ( $p<0.0015)$. However, $\log _{\mathrm{e}} \mathrm{sGaw}$ before active pressure-packed aerosol and active nebuliser solution ( 0 minutes and 


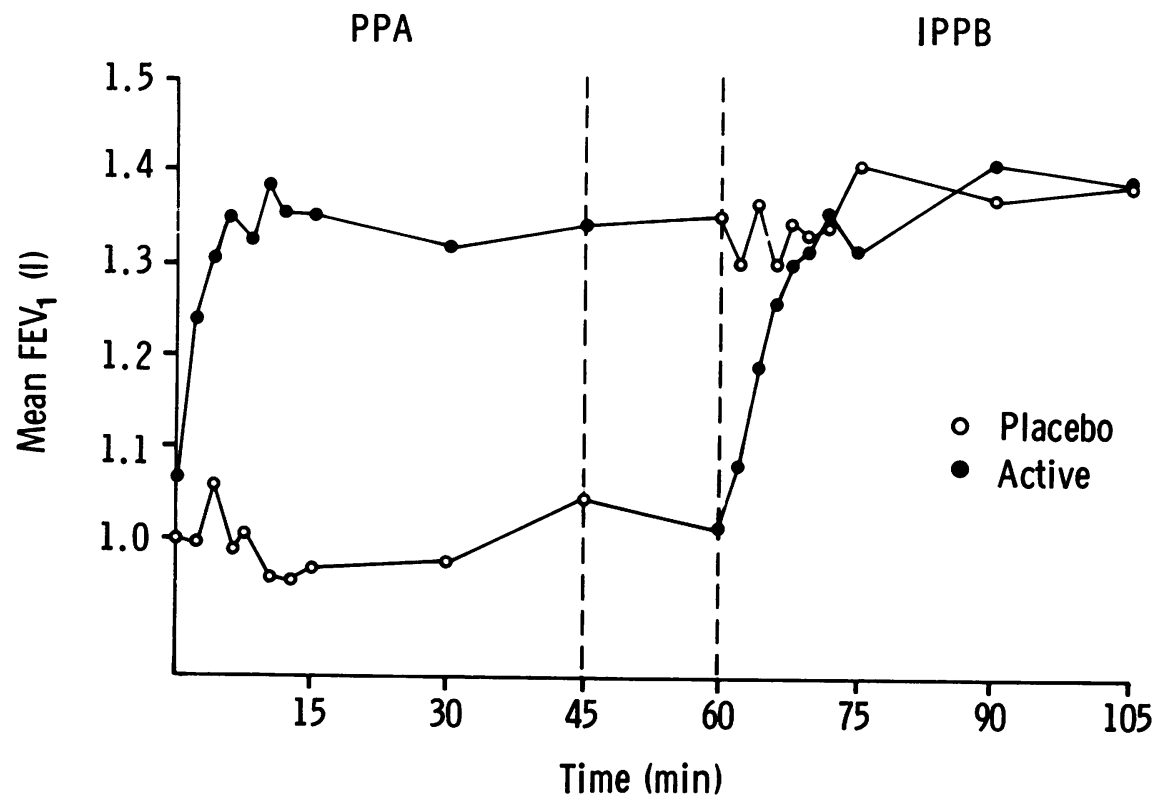

Fig 1 Mean FEV after salbutamol given by pressure-packed aerosol $(P P A)$ and intermittent positive-pressure breathing (IPPB).

PPA

IPPB

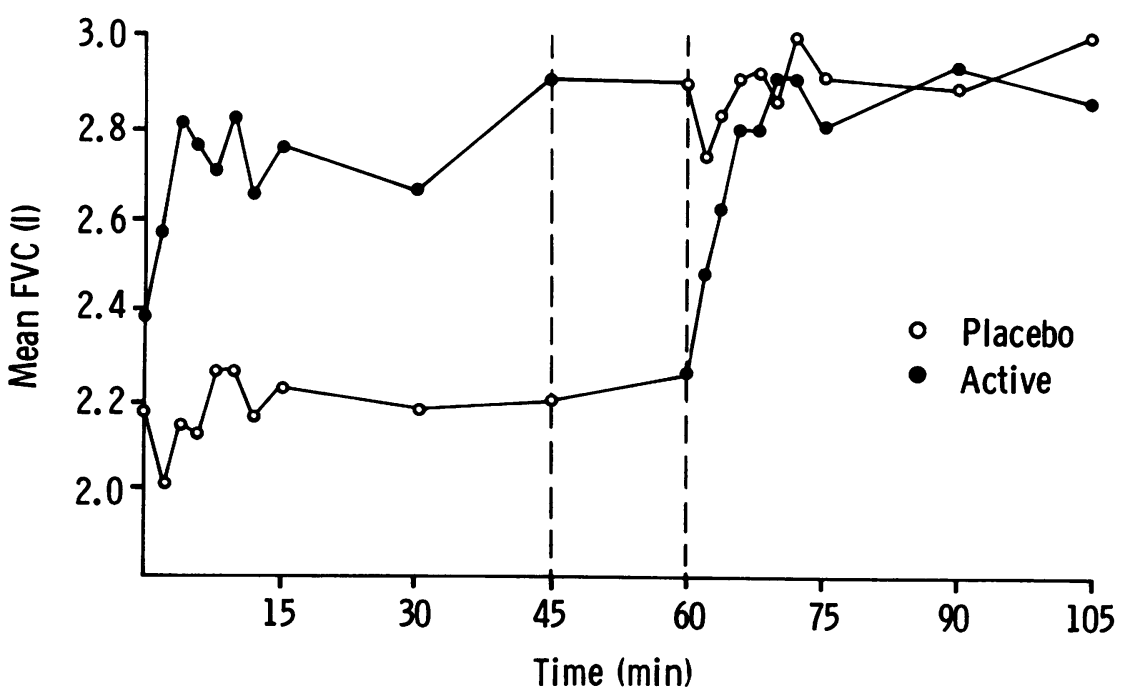

Fig 2 Mean FVC after salbutamol given by pressure-packed aerosol (PPA) and intermittent positive-pressure breathing (IPPB).

Time (min) 
Table 1 Changes in $\log _{e} s G a w$ and thoracic gas volume (TGV) on the two treatment schedules

\begin{tabular}{|c|c|c|c|c|c|c|}
\hline \multirow[b]{2}{*}{ Time (min) } & \multirow{2}{*}{$\frac{\text { Active PPA }}{0}$} & \multicolumn{2}{|c|}{ Placebo IPPB } & \multicolumn{2}{|c|}{ Placebo PPA } & \multirow{2}{*}{$\frac{\text { Active IPPB }}{105}$} \\
\hline & & 45 & 105 & 0 & 45 & \\
\hline 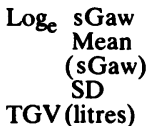 & $\begin{array}{c}-3.146 \\
(0.043) \\
0.376\end{array}$ & $\begin{array}{c}-2.512 \\
(0.081) \\
0.476\end{array}$ & $\begin{array}{c}-2.464 \\
(0.085) \\
0.579\end{array}$ & $\begin{array}{c}-2.922 \\
(0.054) \\
0.421\end{array}$ & $\begin{array}{c}-3.084 \\
(0.046) \\
0.480\end{array}$ & $\begin{array}{c}-2.728 \\
(0.065) \\
0.652\end{array}$ \\
\hline $\begin{array}{l}\text { Mean } \\
\text { SD }\end{array}$ & $\begin{array}{l}5 \cdot 11 \\
1 \cdot 73\end{array}$ & $\begin{array}{l}4 \cdot 6 \\
1 \cdot 61\end{array}$ & $\begin{array}{l}4 \cdot 51 \\
1 \cdot 38\end{array}$ & $\begin{array}{l}5 \cdot 35 \\
2 \cdot 12\end{array}$ & $\begin{array}{l}5.66 \\
2.45\end{array}$ & $\begin{array}{l}4.42 \\
1.25\end{array}$ \\
\hline
\end{tabular}

PPA-pressure-packed aerosol; IPPB—intermittent positive-pressure breathing.

Table 2 Changes in pulse rate on the two treatment schedules

\begin{tabular}{|c|c|c|c|c|c|c|c|c|c|c|c|c|c|c|}
\hline \multirow[b]{2}{*}{ Time (min) } & \multicolumn{3}{|c|}{ Active PPA } & \multicolumn{4}{|c|}{ Placebo IPPB } & \multicolumn{4}{|c|}{ Placebo PPA } & \multicolumn{3}{|c|}{ Active IPPB } \\
\hline & 0 & 15 & 30 & 45 & 75 & 90 & 105 & 0 & 15 & 30 & 45 & 75 & 90 & 105 \\
\hline $\begin{array}{l}\text { Pulse rate } \\
\text { Mean } \\
\text { SD }\end{array}$ & $\begin{array}{l}96 \\
17\end{array}$ & $\begin{array}{r}112 \\
21\end{array}$ & $\begin{array}{r}108 \\
18\end{array}$ & $\begin{array}{r}111 \\
19\end{array}$ & $\begin{array}{r}108 \\
22\end{array}$ & $\begin{array}{r}107 \\
16\end{array}$ & $\begin{array}{r}109 \\
19\end{array}$ & $\begin{array}{l}92 \\
21\end{array}$ & $\begin{array}{r}101 \\
21\end{array}$ & $\begin{array}{l}97 \\
20\end{array}$ & $\begin{array}{l}97 \\
20\end{array}$ & $\begin{array}{r}104 \\
19\end{array}$ & $\begin{array}{r}106 \\
19\end{array}$ & $\begin{array}{r}104 \\
20\end{array}$ \\
\hline
\end{tabular}

PPA-pressure-packed aerosol; IPPB—intermittent positive-pressure breathing.

45 minutes respectively) did not differ $(p>0.5)$ and a greater percentage change in $\log _{e} s G a w$ occurred after salbutamol from a pressure-packed aerosol than after intermittent positive-pressure breathing nebulisation $(p<0.05)$.

Thoracic gas volume Baseline thoracic gas volume was similar on the two treatment days $(p>0.4)$. After the active pressure-packed aerosol there was a significant fall in thoracic gas volume $(p<0.05)$, which did not occur with placebo $(p>0 \cdot 2)$. The placebo nebuliser solution did not result in a further change $(p>0.5)$ but nebulised salbutamol did cause a fall $(p<0.02)$. Before the two active treatments thoracic gas volume was similar $(p=0.2)$ and the percentage change produced was not significantly different $(p>0 \cdot 1)$.

Pulse rates The changes in pulse rate are shown in table 2 . There was a statistically significant increase in pulse rate at all times of recording after $4.8 \mathrm{mg}$ salbutamol delivered by pressure-packed aerosol and nebuliser. The pulse rate did not change significantly after use of the placebo pressurepacked aerosol or nebuliser. The percentage change was similar for the two delivery methods $(p=0 \cdot 1)$.

Side effects One patient developed tremor when receiving salbutamol from both the nebuliser and the pressure-packed aerosol, one when receiving nebulised drug, and one after the pressure-packed aerosol.

\section{Discussion}

A 4.8-mg dose of salbutamol given by pressurepacked aerosol has been shown to be just as effective in terms of improvement in FEV 1 and FVC as the same dose given by intermittent positivepressure breathing nebulisation in a group of chronic asthmatic patients with a relatively poor response to standard $200-\mu \mathrm{g}$ doses. Changes in thoracic gas volume and pulse rate did not differ significantly with the two delivery techniques, although the pressure-packed aerosol produced a significantly larger change in sGaw than did nebulisation. That a roughly equivalent dose of bronchodilator given by the two methods produced similar overall changes in respiratory function indicates that disparity in dosage has been the important factor in determining the outcome of previous comparative studies of pressure-packed aerosol and intermittent positive-pressure breathing ${ }^{4-6}$ and not the delivery technique itself.

Although not yet of proved value, outpatient and domiciliary nebulisation of bronchodilators is currently in vogue for chronic airflow obstruction. ${ }^{1011}$ The use of cylinder or compressor-driven nebulisers, whether or not they are of the intermittent positive-pressure breathing type, by patients at home has financial implications. Firstly, the units originally available were in the main intermittent positive-pressure breathing devices and therefore expensive. Less expensive devices not using intermittent positive-pressure breathing are now avail- 
able but $£ 60-100$ is required for each unit. In some areas hospitals provide the equipment, in others the patient buys his own machine. Secondly, arrangements for regular servicing and safety checks have to be made. If appreciable numbers of patients receive such treatment, the financial commitment in terms of capital investment, drugs, and revenue consequences, including technicians' time or service contracts, could become considerable.

We have shown that a high dose of salbutamol from a pressure-packed aerosol will produce worthwhile improvement in respiratory function equal to that achieved by the same dose given by intermittent positive-pressure breathing in severe chronic asthma. We have not found side effects or tachycardia to be unacceptable when compared with those produced by the established technique of giving high doses by nebulisation. Were a high-dose inhaler available, it would be of advantage to those who do not respond optimally to current pressure-packed aerosols. It might be argued that a high-dose pressure-packed aerosol could be abused but a respirator solution and nebuliser unit for domiciliary use have the same potential.

Whether regular high doses of bronchodilator are of benefit in chronic airflow obstruction remains to be determined; but the use of a high-dose pressure-packed aerosol rather than intermittent positive-pressure breathing or other forms of nebulisation would have clear advantages in terms of cost, convenience, and simplicity.

We thank Dr LA Philips for advice and Allen and Hanbury Ltd for the material used in the study.

\section{References}

' Bloomfield P, Carmichael J, Petrie JR, Jewell NP, Crompton GK. Comparison of salbutamol given intravenously and by intermittent positive-pressure breathing in life-threatening asthma. $\mathrm{Br} \mathrm{Med} J$ 1979;i:848-50.

2 Williams S, Seaton A. Intravenous or inhaled salbutamol in severe acute asthma? Thorax 1977;32:555-8.

${ }^{3}$ Campbell IA, Hill A, Middleton H, Momen M, Prescott RJ. Intermittent positive pressure breathing. $\mathrm{Br}$ Med J 1978;i: 1186.

4 Cayton RM, Webber B, Paterson JW, Clark TJH. A comparison of salbutamol by pressure packed aerosol or nebulisation via IPPB in acute asthma. $\mathrm{Br} J \mathrm{Dis}$ Chest 1978;72:222-4.

${ }^{5}$ Choo-Kang YFJ, Grant IWB. Comparison of two methods of administering bronchodilator aerosol to asthmatic patients. Br Med J 1975;ii:119-20.

${ }^{6}$ Berend N, Webster J, Marlin GE. Salbutamol by pressure packed aerosol and by intermittent positive pressure ventilation in chronic obstructive bronchitis. $\mathrm{Br} J$ Dis Chest 1978;72:112-4.

${ }^{7}$ Newman SP, Pavia D, Sheahan NF, Moren F, Clarke SW. Deposition of pressurised aerosols in the lung using radio labelled particles. Thorax 1980;35:234.

${ }^{8}$ Shenfield GM, Evans ME, Walker SR, Paterson JW. The fate of nebulised salbutamol administered by intermittent positive pressure respiration to asthmatic patients. Am Rev Respir Dis 1973;108:501-5.

${ }^{9}$ Guyatt AR, Alpers JH. Factors affecting airways conductance: a study affecting 752 working men. J Appl Physiol 1968;24:310-6.

${ }^{10}$ Connellan SJ, Wilson RSE. The use of domiciliary nebulised salbutamol in the treatment of severe emphysema. Br J Clin Pract 1979;3:135-6.

${ }^{11}$ Wilson RSE, Connellan SJ. Domiciliary nebulised salbutamol solution in severe chronic airways obstruction. Thorax 1980;35:873-6. 